Methods The exercise took place at night on September 26, 2016. Fifteen days after, a questionnaire was sent to nurse students who took part as victims. Descriptive results are given in percentages and averages.

Result 126 participants did answer (82.4\%). The average age was 23 years and $86 \%$ were women.

$20.7 \%$ considered themselves as anxious or very anxious and $5.9 \%$ reported poor or very poor sleep. Their roles were assigned to severely injured (30\%), involved (25\%), deceased (21\%), moderately injured (14\%) and hostages (10\%).

During terrorist attack, $56.9 \%$ found that they were in a uncomfortable situation. $85 \%$ of the participants considered the attack as fairly or very impressive and $79 \%$ were afraid at some point during the exercise. For those who were scared, half said that this fear remained after the end of the exercise. 21 participants felt necessary to have an interview with a psychologist.

More than 23\% of participants felt that this exercise had been fairly or very disruptive and would deny or hesitate to participate again in a similar exercise.

Discussion Acting as a simulated victim, in a hyper-realistic live exercise, generate stress, fear or anxiety. In order not protect from unnecessary stress, it is essential for organisers to take this in consideration and offer to those who play victims acceptable conditions of comfort. Further studies are required to recognise factors that cause a predisposition of stress in such situations and set aside those with risks.

\section{TRAINING SESSIONS FOR OCCUPATIONAL PHYSICIANS AND NURSES: THE ADDED VALUE OF A SATISFACTION QUESTIONNAIRE}

Anna Ozguler*, Michel Baer, Guillaume Douge, Thomas Loeb. SAMU92, APHP, Garches, France

\subsection{6/oemed-2018-ICOHabstracts.327}

Introduction An Emergency Medical Service (EMS) offers each year Medical Emergency Days (JAMU) alternating occupational physicians and nurses. Its goal is to provide participants with theoretical training and practical workshops on varied aspects of emergency medicine.

Satisfaction of participants was evaluated since 2008 .

Methods A questionnaire was distributed during the JAMU since 2008. Questions concerned their overall satisfaction and their satisfaction concerning program content. They were also asked to answer which topics they expected to see developed and how they considered their emergency practice would change on a scale from 0 (as difficult as before training) to 10 (much easier than).

Result Since 2008, 1363 participants answered to this satisfaction questionnaire (48\%). Participation to this questionnaire rose from $28 \%$ in 2008 to $56 \%$ in 2017 . Nurses tend to answer more often (53\%) than physicians (43\%).

Overall satisfaction and satisfaction concerning program content rose from $84 \%$ of satisfied or very satisfied to $98 \%$ for both items these 2 last years.

The topics they expect to see addressed focus on psychiatric emergencies and technical procedures (infusion set or implementing an emergency kit). Other topics evolved these last years, such as CBRN threats or how to face a terrorist event.
Participants rated their ability to diagnose in the field of emergency medicine with a score that evolved from 6.5 in 2008 to 7.9 in 2016, and their ability to perform procedures with score that increased from 6.2 in 2008 to 8.03 in 2016.

Discussion Satisfaction questionnaire showed a growing interest for these training days, participants answered more often, they declared being more satisfied and more able to perform diagnosis and perform technical procedures. The program evolved taking into account not only their suggestions but also the terrorist environment, which may have an influence in the growing participation and interest of participant.

\section{TRAINING NEEDS FOR EMERGENCY CARE IN ORGANISATIONAL SETTINGS- 'FROM FIRST AID TO EMERGENCY COORDINATION'}

${ }^{1}$ Susanne Schunder-Tatzber, ${ }^{2}$ Alexis Descatha, ${ }^{3}$ Pascal Cassan. ${ }^{1}$ OMV Corporate Health Management and Austrian Red Cross, National Training Centre, Vienna, Austria; ${ }^{2}$ Univ Versailles St-Quentin, Versailles, France; Inserm, and UMS 011 UMR1168, F-94807, Villejuif, France; ${ }^{3}$ Global First Aid Reference Centre of the International Federation of Red Cross and Red Crescent Societies, Paris, France

\subsection{6/oemed-2018-ICOHabstracts.328}

Introduction Accidents and acute medical events at workplaces are unfortunately not rare events - ILO estimates that 313 million people are injured and 350.000 are killed in work related accidents annually1.Besides risk assessment and safety measures to reduce the number of incidents every company has to develop specific emergency plans to support and treat injured and critically ill employees as the worksite, which has to include First Aid as starting point for the 'Chain of survival'.

1 IOCH Newsletter Volume 13, Nr. 2,3. - page 1: Message from the new ICOH president Jukka Takala.

Methods In an electronic survey which was sent out to international Red Cross/Red Crescent colleagues and Occupational health specialists interesting insight in the global provision of First Aid at workplaces and especially on cardiac arrest could be gained.

Result More than 100 answers from different part of the world demonstrate that in $3 / 4$ of the country's First Aid is legally required and in about $70 \%$ risk assessments define the number of trained First Aiders. Emergency medical drills in companies are only mandatory in 50\% of the countries.

The fact that in $40 \%$ of the answers the average responding time of an EMS is more than $30 \mathrm{~min}$ in rural areas and $30 \%$ up to 20 in urban zones gives a clear mandate to improve the training of First Aid and numbers of First Aid trainers.

Discussion Some best practices and ideas on how to improve the quality of training First Aiders and other health care provider will be discussed.

\section{THE STATUS OF EMERGENCY PREPAREDNESS AND RESPONSE IN PETROL STATIONS IN BUSHENYI AND SHEEMA DISTRICTS IN UGANDA}

${ }^{1}$ Tom Eliatu, ${ }^{2}$ Deogratius Kaheeru Ssekimpi. 'Ministry of Gender, Labour and Social Development, Department of Occupational Safety and Health, Uganda, Kampala; ${ }^{2}$ Uganda National Association of Community and Occupational Health

10.1136/oemed-2018-ICOHabstracts.329 